\title{
Time Management in the Nigerian Civil Service: An Imperative Value For Nigeria's Reforming Economy
}

\author{
Olusola Frederick Ahmadu \\ Covenant University, Ota
}

DOI: $10.36108 / \mathrm{NJSA} / 7002 / 50(0150)$

Vol. 5 Issue 1, 2007

\begin{abstract}
The Nigerian public service has been undergoing gradual and systematic reforms and restructuring since 1999 after decades of military rule. The reforms are meant to meet the challenges of civil rule, democracy, good governance, and globalization. Despite the various public and civil service reforms of the Nigerian civil service is still slow in responding to technological changes and modern organizational methods. It is characterized by poor working arrangements and gross in discipline. In most organizations in Nigeria, lots of man-hour is wasted on unproductive activities. This problem of wasted man-hour seems to have been taken for granted in Nigeria and it has not been deliberately addressed in our reform agenda. Time management is an important factor in organizational efficiency and effectiveness. It is against this backdrop that this paper examines the role of time management in achieving the reform agenda. Secondary data was used to examine the concept of time in advanced capitalist economies, Africa and Nigeria. It was found that poor remuneration, lack 'of motivation, especially intrinsic motivation and poor work arrangements were responsible for poor work ethics in the public/civil service in Nigeria.
\end{abstract}

\section{Introduction}

Following years of economic stagnation, Nigeria embarked on a comprehensive reform programme during the second term of the Olusegun Obasanjo's administration. The programme was based on the National Economic Empowerment and Development Strategy (NEEDS) and focused on four major areas: improving the macroeconomic environment, pursuing structural reforms, strengthening public expenditure management, and implementing institutional and governance reforms (Okonjo-Iweala \& OsafoKwaako, 2007).

The Nigerian public service in general and civil service in particular have been undergoing gradual and systematic reforms and restructuring since May 29, 1999 after decades of military rule. The reforms are meant to meet the challenges of civil rule, democracy, good governance and globalization (Babura, 2003). According to Philips (1990), public service is the instrument which government uses to regulate' and manage all aspects and areas of the society. He also observed that the condition of a society is largely determined by the public service. He however contended that some of the reforms especially the 1988 civil service reforms introduced profound distortions in the civil service. Ayida, in Ajulo, (1998) argued that the harm done during the reforms was so much and so deep that it would take patience and determination to restore the lost glory of the service. 
Despite the various reforms of different governments, the Nigerian civil service is still slow in responding to technological changes and modern organizational methods, characterized by poor work arrangement, highly hierarchical operational structure, un-streamlined organizational structures, inadequate remuneration of civil servants vis-a-vis their counterparts in other sectors in the face of ever-increasing inflation, absence of basic work materials, tools and equipment and a grossly indisciplined workforce. The staff in this work force are frustrated, poorly paid, have low morale, exhibit laxity, poor and negative work ethics, declining in efficiency, effectiveness and productivity (Babura, 2003).

This paper examines the concept of time management as it obtains in advanced capitalist economies, the African economic system and Nigeria in particular. The paper shows the imperativeness of time management as employed in every industrialized society as an important value for organizational effectiveness and efficiency. This challenge of time management seems to be a missing ingredient in our reform agenda, which the paper addresses as an important factor that should not be overlooked for the reason of effectiveness and efficiency in every facet of Nigeria's economy, particularly the Nigerian Civil Service.

\section{What is Time Management?}

Time management is a set of principles, practices, 'skills, tools, and system that work together to help you get more value out of your time with the aim of improving the quality $\sim \mathrm{f}$ your life. According to Drucker (2001), time is a unique resource. One cannot rent, hire, buy, or otherwise obtain more time. The supply of time is totally inelastic. No matter how high the demand, the supply will not increase. There is no price for it and no marginal utility curve for it. Moreover, time is totally perishable and cannot be stored. Yesterday's time is gone forever and will never come back. Time is therefore, always in exceedingly short supply. Within limits, we can substitute one resource for another, but there is no substitute for time.

Everything requires time. It is the only truly universal condition for human continuous existence. All work takes place in time and uses up time. Most Nigerians take for granted this unique, irreplaceable, and necessary resource. Nothing else, perhaps, distinguishes effective executives as much as their tender loving care of time.

Time management skills according to Mind Tools (2007) helps one become highly effective by demonstrating how to identify and focus on the activities that give you the greatest returns in an organization. Investing in these time management activities will actually save you time, helping you work smarter, not harder. Time management skills are essential skills for effective people. Employing time management skills will enable one to function effectively, even under intense pressure. Time management connotes beating work overload, increased effectiveness and achieving more. At the 
heart of time management is an important shift in focus: concentrate on results, not on being busy.

Many people spend their days in a frenzy of activities, but achieve very little because they are not concentrating on the right things. This could be summed up in what is called the Pareto Principle - the 80:20 rules. This rule argues that typically $80 \%$ of unfocused effort generates only $20 \%$ of results. The remaining $80 \%$ of results are achieved with only $20 \%$ of the effort.

While the question of duration has traditionally represented the focus of union management relations on working time, in recent years this has been increasingly supplemented by a growing managerial concern with the more effective organization and utilization of working time. As a consequence, negotiations over the length of working hours have been increasingly tied to issues relating both to the arrangement of those hours and a tighter definition of the working period through, for example, changes to the taking of breaks and increased discipline over start and stop times (Sission,"1994).

People have insufficient time to meet all of the demands on them from work and their lives outside of work (Perlow, 1999). The actual use of time at work and the impact their use of time has on other individuals and the groups to which the individuals belong, reveal the problematic nature of the current way of using time. The existing literature on time usage contributes to a partial understanding of how and why individuals do and should spend their time at work (Perlow, 1999). However, Brannick and Levine (2002) direct time study toward discovering the time taken to complete a given task or the time allocated to different tasks that comprise a job.

Both scientific management (Taylor, 1911) and more recently, time management (e.g. Brooks and Mullins, 1989, Jones, 1993; Covey, Merrill, 1994; Griessman, 1994) further prescribe the ways in which people should use their time at work. Time management could be defined as the proper delegation of the time we have in order that the most important tasks are achieved before the less important ones. It means getting the maximum value and benefit out of every activity accomplished, no mater how small or big and it also means accepting that not everything can be completed at the same time and that there are things that can be achieved within the limitations of our human faculties.

To come to terms with our mortality is to realize that our time is limited McConnel, Brue and Macpherson(2003) argue that individuals who have a fixed amount of time available must decide how that time should be allocated among various tasks.

\section{Time Management and Global Capitalist Economy}

Capitalism is the most successful wealth-creating economic system that the world has ever known. Capitalism creates wealth through advancing continuously to higher levels of productivity and technological sophistication. Technological progress, the ultimate driving force of capitalism, requires continuously abandoning obsolete value systems 
economic sectors, and even human skills. The system rewards the adaptable and efficient; it punishes the redundant and the less productive. Advanced capitalist economic value poses a serious threat to traditional social values, beliefs and institutions. The success of advanced capitalist economies is anchored on the principle of organizational efficiency and effectiveness.

Frederick Taylor's scientific management approach assumes that human beings by nature, are selfish, lazy, dislike work and responsibility unambitious, passive and resistant to organizational goals, and hence, must be coerced, directed, commanded and controlled in order to achieve set objectives. Taylor believed that a combination of coercion and economic/financial incentives would lead to high performance by workers (Onyeonoru, 2005). The advanced capitalist economies progress through the principles of scientific management with elements of the human relations approach. Workers are controlled but are highly financially motivated; they place a high value on efficient time management. This is what is conspicuously missing in Nigeria's reforming economy. Nigeria's economy is constrained by Africa's time management style, thus it has become difficult for the new class of the Nigerian civil service, in spite of reforms to adjust to the global capitalist order.

Time is and always has been seen, at least by the advanced capitalist economies as the most precious commodity. However, from the looks of the global economy, it is very apparent that time is being taken very much for granted more so than ever before (Shalman, 2008). It is a fact that most productive people whether in advanced economies or less advanced or developing economies value time. In advanced economies particularly, time is wisely invested rather tan spent. Time is one of the most essential ingredients for high productivity whether in terms of individuals or the organizations.

In essence, work is valued in terms of the number of hours put in. in other words, work in advanced capitalist economies is valued per hourly basis. Thus at work, a worker is never permitted to spend the working hours on gossip, play or on any time-wasting activity.

The interesting thing however, about global time management and human nature is the fact that no matter which part of the world we live in, we tend to waste time in a very similar way. It almost seems like a conspiracy. Thus, time management problem is not peculiar to Africa or Nigeria, it is a universal phenomenon. It is just a matter of degree from one economy to the other.

\section{Some Global Time Management Pitfalls}

Shalman (2008) identifies some global time management pitfalls which include the following:

- Work-Home Commute

In every major city in the world there are people travelling over an hour to reach their work destinations from home. In Nigeria in particular, some workers spend over three hours getting to work and ever four hours on the road from work to their homes. People experience huge waste of time that 
could be used working or spent with family; huge waste of money on transport fare, fuel and cars as the case may be. This also results in stress and fatigue both at work and at home.

- $\quad$ Mind-Numbing Television

The world sits hypnotized in front of television screens for hours each day to watch television programmes, soap operas and movies. This is a major global time-waster. People with ambition should learn to unplug the television unless when absolutely necessary and spend prime time doing activities that nourish their souls, pursue their dreams, and at the same time spend quality time with their family and friends.

- Entertaining Bad Company

The company you keep determines what accompanies you. Globally there are people who keep the company of people that do not influence their lives positively. The best way to deal with bad company is to get rid of them. Surround yourself with good mentors, achievers and goal-getters. It is also global that some people have no vision to strive for. It is common seeing people living a life without vision, without a major goal and life plan. Such people no matter which part of the world they live in spend their days drifting. The antidote to this is to spend some time on planning what you want out of life.

- Excessive Sleepiness

This is also a time management pitfall which could be as a result of ill health, over-eating, drugs, depression, etc. The solution to this is to have a real purpose in life, eat right and never mistake over sleeping for rest.

\section{African Economic System and Time Management}

Time has been conceptualized in various ways. However, for the purpose of this paper, time shall be defined as a non-spatial continuum in which even occur in apparently irreversible succession from the past through the present to the future. It is a period or periods necessary or available for a given activity. However, there is a unique way in which Africans are said to conceptualize time. This African concept of time may help to explain beliefs, attitudes, practices and general way of life of African peoples, not only in the traditional set up but also in the modern situation- whether of political, economic, educational or church life (Mbiti, 1969).

Indigenous African cultures seem to have a highly flexible sense of time, at least as portrayed by the well- known saying among native Africans that "there is no hurry in life". Though somewhat too stereotyped to accurately describe time usage among any specific African cultural group, however, the adage has some element of truth to it. In Africa, most capable workers are reputable for taking their time, so that the key word is effectiveness (what is 
finally achieved) rather than efficiency (time conservation in goal accomplishment).

The question of time is of little or no academic concern to African peoples in their traditional way of life (Mbiti, 1969). For them, time is simply a composition of events which have occurred, those which are taking place now and those which are immediately to occur. What has not taken place or what has no likelihood of an immediate occurrence falls in the category of "No time". What is certain to occur, or what falls within the rhythm of national phenomena, is in the category of inevitable or potential time.

The most significant consequence of this is that, according to traditional concepts, time is a two-dimensional phenomenon, with a long past, a present and virtually no future (Mbiti, 1969). The linear concept of time in western thought, with an indefinite past, present and infinite future is practically foreign to African thinking. Actual time to a typical African is what is present and what is past. It moves "backward" rather than "forward"; and people set their minds not on future things, but chiefly on what has taken place.

When traditional Africans reckon time, it is for a concrete and specific purpose, in connection with events but not just for the sake of mathematics. Since time is a composition of events, people cannot and do not reckon with it in a vacuum. Instead of numerical calendars, there are what one would call phenomenon calendars, in which the events or phenomena which constitute time are reckoned or considered in their relation with one another and as they take place, i.e. as they constitute time; for example, an expectant mother counts the lunar months of her pregnancy: a traveller counts the number of days it takes him to walk (in former years) from one part of the country to another. The day, the month, the year, one's lifetime or human history, are all reckoned according to their specific; events, for it is these that make them meaningful.

In the western societies, time is a commodity which must be utilized, sold and bought; but in traditional African life, time has to be created or produced. Man is not a slave of time; instead, he "makes" as much time as he wants (Mbiti, 1969). Mbiti argued that Africans either wait for time, or "produce" time. The basic concept of time influences the life and attitude of African peoples in the villages, and to a great extent to those who work or live in the cities as well. Among other things, the economic life of the people is deeply bound to their concept of time. However Mbiti's perception of African time has been criticized by Gbadegesin (1991). He says Mbiti's thesis is merely' a communal world- view without an attempt to evaluate it.

Oke (2005) has also critically evaluated the work of Mbiti on African time. According to Mbiti, the people of Africa believe that only God exists infinitely, and can know beyond the present, they may, for instance, be comfortable with a short term ambition or expectation in life. They may not be motivated to strive for progressive social and societal development which is a distant futuristic phenomenon. They may also lack material accumulative tendencies, since, ideally, one only accumulates for future utility. This is, 
however very sharply contradicted by the observable lives of many Africans in the home, in politics, and in business, both in traditional and in contemporary times. Many of them procreate profusely, acquire property voraciously, and engage in cash crop plantations laboriously, have inheritance procedures, embezzle in public life excessively, engage in several forward-looking sharp practices in business, play hard rough 'sit-tight' politics, struggle for education and strive to be in good health, traditionally and contemporarily (Oke, 2005).

Oke further argues that although the general laxity of Africans about especially future time, pervades their collective attitude to work. According to him, most Africans could be said to lack' time-discipline', not that they do not have the concept of time. This fact is corroborated by a Yoruba popular saying such as: owuro lojo; akoko ko duro denikan - This means time is very precious. Africans cherish time but we need to effectively manage our time.

This paper strongly agrees with Oke, but at the same time shares some of Mbiti's views of our unprogressive attitude toward time managemen thereby sensitizing us to the fact that it is time we departed from !hi traditional African conception of time if we really want to catch up with th advanced economies. In other words, the paper points out the consequence of holding an unprogressive and outdated idea of time or time-relate pattern of behaviour. Enough of activity without progress! Refoll programme notwithstanding, if not backed with the right attitude, it 11 achieve little or no result. If we continue to use the same solutions to solve same problem we will always arrive at the same results. We need to plan an manage our time. It is an essential ingredient for individual organizational effectiveness and efficiency.

\section{Socio-Cultural Factors Influencing African Time Management}

The influence of culture on economic activities of different societies has been investigated since the beginning of the 20th century. The argument in sociology that individuals affect and are affected by the social structure have been taken to bear on the issue of time management.

Weber (1904) reports in his famous work, 'Protestant ethic and the spirit of capitalism', that the great accumulation of wealth that led to the emergence of capitalism in Europe and North America and which accounted for the level of development witnessed in those societies was a result of protestant ethics. This ethic encouraged abstinence from life's pleasures, an austere lifestyle and rigorous self-discipline. Inglehart (2000), from his study of 65 societies, concludes that economic differences are linked with large' and pervasive cultural differences, and that cultural zones are persistent and long lasting. Adler (1997) also argues that the cultural orientation of a society reflects the complex interaction of values, attitudes and behaviours displayed by its members.

The extended family system or rather, the culture of collectivism is one if not the major factor in our time management challenge. This pitfall affects 
even those who are aware of the value of time management. This is not a condemnation of the culture of collectivism; however, a good time manager should learn to say no to less important matters when necessary. There are things that are out of our control, like a friend or family member in crisis, but there are some things that are a natural result of poor planning or inability to say no to things. This is what Repak (nd) terms "The Tyranny of the Urgent". Africans, no matter the level of family affiliation, as a matter of fact, should never give up on the value of organizing, planning and prioritizing.

Poor infrastructure is one of the banes of effective time management in Africa. Poor infrastructure especially road and electricity are major sources of concern particularly in Nigeria. Lots of man hour is wasted in traffic holdups due to bad roads. In this situation, eve those that are mindful of time are victims of time management. Nigeria's electricity supply is currently in a 'state of emergency'. Tasks cannot be completed or done because of the challenges of inadequate electricity. On some occasions, work that is supposed to be done in-house has to be taken miles away as a result of poor power supply. All these are time management pitfalls. Government should first get things right in the area of infrastructural development before any reform agenda can be effective.

Task interruption is another major pitfall of time management in Africa and it is routine (and in fact quite expected) in a culturally programmed social-psychological milieu where socio-emotional and spiritual experiences take precedence over' the rational and physical requirements for efficient production (Mpofu, D' Amico, Cleghorn, 1996). For example, visitors (be they to homes or work place) are culturally not expected to make appointments and can stay as long as they please. Time orientation is mainly characterized by lack of urgency and patience in respect of their personal conduct. A typical African is at all times regulated by the ethos of his people to the extent that if he enters an industrial society, he has only moved bodily into the culture of advanced industrial society but will feel the influence of his original culture.

\section{Theorizing the Value of Time Management}

A group of factors influencing how a person behaves on the job is that person's values and beliefs about society and organization that have been acquired overtime through the process of socialization. A value, according to DurBrin (2004), refers to the importance a person has attached to a phenomenon. DurBrin further argues that people are not born with a particular set of values. Rather, values are learned in the process of growing up. One important way we acquire values according to DurBrin is through modelling. It is often found that a person who takes considerable pride in his/her work was reared around people who had strong work ethics. Models can be parents, teachers, friends, siblings, public figures or even a country.

Communication of attitudes is another major way of imbibing values The attitude we see directly or indirectly helps shape our values. Unstated 
but implied, attitudes may also shape values. If key people in your life showed no enthusiasm when you talked about work accomplishment, you might not place a high value on achieving outstanding results.

The educational institution is organized in a way that it will teach proper values of time management. This is evident in the way students/pupils are disciplined if they come late to school or fail to submit assignments on time it is also evident in the timing of examination papers, break periods, dining time etc. However, with the decline in the standard of education, the value of time management also declines. The teachers that are supposed to be the custodians of educational values themselves fall short of these values they are supposed to inculcate. They come late to school due mainly to infrastructural problem, particularly bad roads leading to traffic congestion and poor transportation arrangements.

Again, the 'public figures' that are expected to be role models and good examples of universally accepted values of time management are regular latecomers to important occasions. Most pathetically, late coming to important occasions has become a status symbol - the most' significant' figures must come later while others are already seated. This is very unfortunate for our reforming economy where all hands are expected to be on deck. This bad leadership example is a major bane in our quest for an improved economy. It is therefore necessary if not compulsory for our leaders to show good examples of how to move our economy forward.

According to Durbin (2004), workers must be motivated to embrace effective time management. He defines motivation as an energizing force that stimulates arousal, direction and persistence of behaviour. It can also be regarded as both a force within an individual and a process used to get others to expend effort. Self interest plays a key role in motivation. In this paper, theories of intrinsic motivation, job enrichment and Max Weber's protestant ethic and the spirit of capitalism are used to explain the rationale for effective time management.

A major motivational strategy for effective time management value is motivating people through the work itself. Intrinsic motivation, or self management, emphasizes that people are active agents, rather than recipients of environmental forces. Job enrichment capitalizes on intrinsic motivation by adding variety and responsibility to the job. One way of enriching jobs is to encourage employees to craft or personalize their jobs. Three types of job crafting as listed by Durbin (2004) are changing the number and types of tasks, interactions with people and one's view of the job.

In the traditional setting people personalize their jobs because they are involved in the planning and actual execution of the job. But in an advanced capitalist society, the planners of the work are different from the executors of the work. This leads to alienation from the process of production. It could encourage time wasting or absenteeism.

Sociology of time management addresses not only the interdependent work patterns but also the social and temporal contexts of the workplace. 
Managers are encouraged to create an environment in which the right people regularly, easily, and informally have contact with each other. There are benefits to these efforts to enhance interactions and promote collaboration in the workplace. However, proponents of time management assert that individuals can make the necessary changes in their lives to gain control of the situation if they will only invest the effort in mastering the proposed time management tactics (Brooks and Mullins, 1989; Covey, 1989; Jones, 1993; Covey, Merrill, and Merrill, 1994; Griessman, 1994).

A fundamental problem with the existing time management literature is the promotion of individual-level change. These techniques enhance an individual's efficiency and effectiveness. However, when individuals optimize their own time management, work groups as a whole may suffer. To mitigate the challenges faced by employees whose work involves both individual and interactive activities, Per Iow (1999) contends that a new type of collective time management is needed - one that takes into account individuals' interdependent work patterns, the macro context in which they work, and the interconnections between this context and their work patterns.

Max Weber's protestant ethic and the spirit of capitalism emphasized the importance of the value of prudence, savings and investment in the development of western capitalism. Thus there must be the development of essential values in our work environment in Nigeria (in this case, the value of effective time management) to realize the positive effect of any reform agenda.

\section{Time Management within the Nigerian Civil Service}

Most Nigerian civil servants are only aware of their start and stop time of work. However, most cannot account for how the times are spent. Most jobs are unnecessarily delayed, or even postponed simply as a result of poor time management. Most of the time is spent on unimportant activities that are avoidable if there is effective time management. Politicians who are elected for a specific term, usually four years, think they have the whole time in the world. They fail to plan their limited time. They therefore end up as failures. They consequently lobby for elongated tenure. In the alternative, they rig themselves into office at all cost by getting rid of prospective opponents.

The Power Holding Company of Nigeria (PHCN) for example, had on several occasions failed to respond to some urgent situations leading to severe adverse consequences. A collapse of electric pole sometimes hinders business activities of people for several months without any attention from the company. This time management lag on the part of PHCN has adversely affected serious minded people and their businesses and has encouraged the lazy ones to drift. Huge casualties and loss of millions of naira have been the experience in Nigeria when fire outbreaks occur because the Fire Service fails to respond on time. Similarly, many individuals have lost vital opportunities due to failure of mails to get to recipients on time as a result of unnecessary delays predicated on poor time management. 
Thus, we have to plan available time properly. We need to assess how we spend our time, set goals that are achievable, we-must learn how to prioritize our goals and activities, that is, focus on those goals and activities that are of major importance to us, and work on the other goals secondarily. We must also embrace the culture of keeping a schedule. By using a schedule properly, you can: understand what you can realistically achieve with your time; plan to make the best use of the time available; leave enough time for things you absolutely must do; preserve contingency time to handle the unexpected and minimize stress by avoiding over-commitment to yourself and others.

\section{Developing Proper Attitudes and Values:}

To be effective in an organization, one's own values must be compatible with the organization's values. They do not need to be the same (Drucker, 2001). But they must be close enough so that they can coexist. Otherwise, the person will be frustrated, and may not produce results. He also argues that effective workers do not start with their tasks, they start with their time. And they do not start out with planning. They start by finding out where their time actually goes. Then they attempt to manage their time and cut back unproductive demands on their time. Finally they consolidate their discretionary" time into the largest possible continuing units. This three-step process which involves recording time, managing time and consolidating time is the foundation of executive effectiveness.

Developing good work habits and time management practices is often a matter of developing the right attitude towards your work and toward time. Here we describe a group of attitudes, values and beliefs that can help a person become more productive through better use of time and improved work habits.

Closely related to establishing goals is developing a strong work ethic a firm belief in the dignity and value of work. Developing a strong work ethic may lead to even higher productivity than goal-setting alone. A person with a strong work ethic believes in quality, is highly motivated and minimizes time wasting activities. In other words, we must learn to work smarter, not harder - invest some time on critical thinking and come up with appropriate means of achieving a goal.

\section{Pruning the Time-Wasters}

Poor management wastes everybody's time. Above all, it wastes the manager's time. Drucker (2001) identifies four major time-wasters caused by management and organizational deficiency as discussed below.

1. The first organizational time-wasters results from lack of system or foresight. The symptom to look for is the recurrent "crisis" (e.g. the Niger Delta crisis that seems to defy solutions due to lack of planning and foresight).

2. Time-waste often results from overstaffing. If a workforce is too small for the task, the work may suffer, if it gets done at all. Much common 
is the workforce that is too big for effectiveness, the workforce that spends an increasing amount of time "interacting" rather than working. If a manager spends more than a small fraction of his time on "problems of human relations," on feuds and frictions, on jurisdictional disputes and questions of cooperation, and so on, then the workforce is almost certainly too large. In a lean organization people have room to move without colliding with one another and can do their work without having to explain it all the time. A good example of this is the number of unproductive ministry staff at all levels of governments in Nigeria, and a number of idle political appointees that have no business in government and could be more useful in other endeavours. This should not be encouraged in a reforming economy like Nigeria.

3. Another common time-waster is mal-organization. Its symptom is an excess of meetings. One either meets or works. One cannot do both at the same time. In an ideally designed structure, everybody would know what he needs to know to do his job. Everybody would have the resources available to him to do his job. We meet because people holding different jobs have to cooperate to get a specific task done. Above all, meetings have to be the exception rather than the rule. An organization in which everybody meets all the time is an organization in which no one gets anything done.

4. This explains the fourth time-waster. Researchers have recognized that interactions facilitate the work process (e.g. Kraut and Glegher, 1990; Fletcher, 1994) and that interruptions have mostly negative effects, on the work process (e.g. Weick, 1995).

5. The last major time-waster is malfunction in information. Good information management is essential for effectiveness in the workplace.

\section{Conclusion}

The major problem with the reforms and restructuring processes is the very poor remuneration package of civil servants. Civil servants are the most disadvantaged and depressed wage earners in Nigeria. The salaries and allowances of civil servants are very poor in relation to the rising cost of living and the amount required for reasonable subsistence (Babura, 3003). In mid-2000, senior level officials were earning less than two hundred US Dollars (US \$200). Also, the gap in salaries between the public and private sector is $300-500 \%$. Even within the public sector, the salary of the civil servants is worse.

No matter how vibrant and reasonable the reform agenda of Nigeria might look, it can only achieve insignificant results if not matched with the right values and attitude. Time management values are not the exclusive preserve of individuals in society, but must also be of concern to organizations and government. Every regime in Nigeria must realize that it 
has a limited time to actualize its promises to the masses, as the constitution may specify. The realization of this would prevent procrastination and will reduce the incidence of clamor for elongation of tenure and also reduce political crisis in the polity.

\section{Recommendations}

To improve workers productivity, it is recommended that the workers be well motivated with both intrinsic and extrinsic factors such as good pay and motivating work environment to prevent sabotage, low morale and drifting. This will also enhance effectiveness and efficiency.

The issue of start and stop hours of work should be reviewed so that any worker that finishes his work on time should spend his remaining productive hours on other profitable endeavours instead of wasting such time in the office doing nothing. In other words, there must be flexibility in time. A common cause of time-waste is largely under the executive's control and can be eliminated by him. If Nigeria is to move forward socio-economically, we must embrace the value of effective time management. It is time we eliminated the 11 African time" syndrome and procrastination. All effective people work on their time management perpetually. They do not only keep a continuing log and analyze it periodically; they set themselves deadlines for the important activities, based on their judgment of their discretionary time.

\section{References}

Adler, N.A. (1997) International Dimensions of Organizational Behaviour. Cincinnati, Ohio: South Western College Publishing.

Ajulo, S.B. (1998) The Office of the Secretary to the Government of the Federal Republic of Nigeria. Ibadan: Vantage publishers.

Babura, A.S.M. (2003) Leading Public Service Innovation: The case of the Nigerian Civil service and Federal Civil Service Commission. Paper presented at the Commonwealth-New Zealand Agency for International Development (NAAID) Programme on "Leading Public Service Innovation, held in Wellington, New-Zealand, from 24th January to 6th March, 3003.

Brooks, W.T. and Mulins, T.W. (1989) High IMPACT Time Management. Englewood Cliffs, NJ: Prentice-Hall.

Brannick, M.T. \& Levine, E. L. (2002) Job Analysis, Methods, Research, and Applications for Human Resource Management in the New Millennium. London: Sage Publications.

Covey, S., Merril, A.R. and Merril, R. R. (1994) First Things First. New York: Simon and Schuster.

Drucker, P.F. (2001) The Essential Drucker. Oxford: Butterwort Heinmann. DuBring, A.J. (2004) Applying Psychology individual and organizational Effectiveness. New Jersey: Pears on Education.

Fletcher, J. (1994) Toward a Theory of Relational Practice in Organizations: A Feminist Reconstruction of Real Work. Unpublished Ph.D. Thesis, 
Boston University. RetrievedfromNK"http://www.findartides.com "on 12th May, 2007.

Gbadamosi, S. (1991) African Philosophy: Traditional Y oruba Philosophy and Contemporary African Realities, New York: Peter Lang.

Griessman, B.E. (1994) Time Tactics of very Successful People. New York: McGraw-Hill.

Inglehart, R. (2000). Culture and Democracy. In L.E. Harrison, and S.P. Huntington (Eds). Culture Matters, Basic Books pp.80-97.

Jones, J.W. (1993) High Speed Management Time Based Strategies for Managers and Organizations. San Francisco: Jossey-Bass.

Kraut, R.E. and Galegher, J. (1990) Patterns of Contact and Communication in Scientific Research Collaborations. In Jolene Galegher, Robert E., Kraut, and Carmen Edigo(ed), Intellectual Teamwork: Social and Technological Foundations of Cooperative Work: 149-172. HILLS.

Mbiti, J.S. (1969) African Religions and Philosophy. London: Heinemann.

McConnel C.R., Brue 5.1., Macpherson D.A.(2003) Contemporary Labour Economics 6th ed. New York: McGraw-Hill.

Mind Tools (2007) Essential Skills for Excellent Career. www.mindtools.com.

Mpofu, E.; D' Amico, M. and Cleghom, A. (1996). Time management practices in an African culture: correlates with college academic grades.

Canadian Journal of Behavioural Sciences. Retrieved on July 20,2008fromhttp://findarticles.com/ p / articles/ mi_qa3717/ is_199604 / ai_n8750161 ?tag=content;coll

Oke, M. (2005) From an African Ontology to an African Epistemology: a critique of J. S. Mbiti on the time conception of Africa. www.questjournal. Net.

Okonjo-Iweala, N. and Osafo-Kwaako, P (2007) Nigeria's Economic Reforms: Progress and Challenges. www.brookings.edu/global.

Onyeonoru, I.P. (2005) Industrial Sociology: An African Perspective. Ibadan: Samlad Printers.

Perlow, L.A. (1999) The Time Famine: Toward a Sociology Work Time. Administrative Science Quarterly, March, 199 . www.findarticles.com.

Phillips, D. (1990) The1988 'Nigerian Civil Service Reforms and their Post1992 Prospects. NISER Occassional paper No. 3: NISER, Ibadan, Nigeia.

Repak, N. (nd). Time Management Retrieved on July 4, 2008 from http:// www.gradresources.org/ article/ time_management.shtml.

Shalman, A. (2008)). 10 Global Time Management Pitfalls and their Cure. $\begin{array}{lllll}\text { Retrieved on July } 20, & \text { from }\end{array}$ http://www.alexshalman.com/blog/2008/03/25/10-global-timemanagement-pitfalls-and-their-cure/

Sisson, K. (1994) Personnel Management: A Comprehensive Guide to Theory and Practice in Britain. United Kingdom. Blackwell Publishers.

Taylor, F. (1911) The Principles of Scientific Management. New York: W.W. Norton. 
Weber, M. (1904). The Protestant Ethic and the Spirit of Capitalism. New York: Routledge.

Weick, K. (1995) Sensemaking in Organizations. Thousand Oaks, CA: Sage. 